\title{
Asynchronous Transmitter Release from Cholecystokinin-Containing Inhibitory Interneurons Is Widespread and Target-Cell Independent
}

\author{
Michael I. Daw, ${ }^{1}$ Ludovic Tricoire, ${ }^{1}$ Ferenc Erdelyi, ${ }^{2}$ Gabor Szabo, ${ }^{2}$ and Chris J. McBain ${ }^{1}$ \\ ${ }^{1}$ Program in Developmental Neuroscience, National Institute of Child Health and Human Development, National Institutes of Health, Bethesda, Maryland \\ 20892, and ${ }^{2}$ Department of Gene Technology and Developmental Neurobiology, Institute of Experimental Medicine, H-1083 Budapest, Hungary
}

\begin{abstract}
Neurotransmitter release at most central synapses is synchronized to the timing of presynaptic action potentials. Here, we show that three classes of depolarization-induced suppression of inhibition-expressing, cholecystokinin (CCK)-containing, hippocampal interneurons show highly asynchronous release in response to trains of action potentials. This asynchrony is correlated to the class of presynaptic interneuron but is unrelated to their postsynaptic cell target. Asynchronous and synchronous release from CCK-containing interneurons show a slightly different calcium dependence, such that the proportion of asynchronous release increases with external calcium concentration, possibly suggesting that the modes of release are mediated by different calcium sensors. Asynchronous IPSCs include very large (up to $500 \mathrm{pA} / 7 \mathrm{nS}$ ) amplitude events, which persist in low extracellular calcium and strontium, showing that they result from quantal transmitter release at single release sites. Finally, we show that asynchronous release is prominent in response to trains of presynaptic spikes that mimic natural activity of CCK-containing interneurons. That asynchronous release from CCK-containing interneurons is a widespread phenomenon indicates a fundamental role for these cells within the hippocampal network that is distinct from the phasic inhibition provided by parvalbumin-containing interneurons.
\end{abstract}

\section{Introduction}

The majority of neurotransmitter release at central synapses is highly synchronized to presynaptic action potentials (Isaacson and Walmsley, 1995). In cultured neurons asynchronous transmitter release also occurs (Goda and Stevens, 1994) and even contributes to the kinetics of seemingly single component EPSCs (Diamond and Jahr, 1995). In cerebellum, asynchronous release from granule cells was identified in situ leading to the hypothesis that residual intracellular $\mathrm{Ca}^{2+}$, which is thought to be responsible for frequency dependent facilitation (Younkin, 1974; Landfield et al., 1986), may also cause asynchronous transmitter release (Atluri and Regehr, 1998). The differential mechanisms responsible for the two modes of release are unresolved, with both higher (Goda and Stevens, 1994) and similar (Sun et al., 2007) calcium affinity processes being linked to asynchronous release. It has also been hypothesized that asynchronous and synchronous release use the same mechanism, with the former oc-

Received Dec. 2, 2008; revised July 6, 2009; accepted July 13, 2009

This research was supported by the Intramural Research Program of the National Institute of Child Health and Human Development (NICHD). C.J.M. was supported by an NICHD intramural research award. Thanks to Josh Huang for the generous gift of the B13 PV-GFP mouse line. We thank Jeff Diamond, Ken Pelkey, and Christine Torborg for comments on this manuscript. We also thank Brian Jeffries for expert technical assistance and Jeff Diamond for assistance with deconvolution analysis. We thank Bruno Cauli and Hélène Geoffroy for sharing primer sequences.

Correspondence should be addressed to Michael I. Daw, Program in Developmental Neuroscience, National Institute of Child Health and Human Development, National Institutes of Health, Room 3c705, Building 35, 35 Convent Drive, MSC 3715, Bethesda, MD 20892-3715. E-mail: dawmicha@mail.nih.gov.

DOI:10.1523/JNEUROSCI.5760-08.2009

Copyright $\odot 2009$ Society for Neuroscience ～0270-6474/09/2911112-11\$15.00/0 curring after the depletion of the readily releasable pool of vesicles (Lu and Trussell, 2000; Otsu et al., 2004).

Inhibitory synaptic transmission in the hippocampus is mediated by a variety of local interneuron classes showing unique patterns of inputs and outputs and synaptic properties, which vary dependent on the identity of both the presynaptic and postsynaptic cell (Freund and Buzsáki, 1996; McBain and Fisahn, 2001; Somogyi and Klausberger, 2005). One of the primary roles of interneurons is to entrain the timing of action potential firing in pyramidal cells (Pouille and Scanziani, 2001) and consequently to synchronize large populations of cells during network oscillations (Whittington and Traub, 2003). Indeed, the firing of different classes of interneurons during discrete phases of these oscillations (Klausberger and Somogyi, 2008) suggests that specific roles in oscillatory activity may be one of the main reasons for the wide variety of interneuron classes. Such roles in temporally precise patterns of activity must require highly coordinated firing of interneurons and synchronized transmitter release.

In the dentate gyrus region of the hippocampus, however, a class of cholecystokinin (CCK)-containing interneurons targeting the proximal dendritic region of dentate granule cells shows a strikingly large component of asynchronous release in response to trains of action potentials. In contrast, somatically targeted parvalbumin (PV) containing interneurons exhibit almost exclusively synchronous release (Hefft and Jonas, 2005). Such asynchronous release is inconsistent with the role in close synchronization of target cell action potential timing described above. Multiple classes of CCK-containing interneurons exist in the hippocampus (Somogyi and Klausberger, 2005) targeting dif- 
Table 1. PCR primers

\begin{tabular}{|c|c|c|c|c|c|}
\hline Marker & Genbank\# & First $P C R$ primers & Size (bp) & Second PCR primers & Size (bp) \\
\hline \multirow[t]{2}{*}{ CCK } & \multirow[t]{2}{*}{ NM 031161.2} & Sense, 16:TGTCTGTGCGTGGTG ATGGC ${ }^{a}$ & \multirow[t]{2}{*}{554} & Sense, 192:ATACATCCAGCAGGTCCGCAA ${ }^{a}$ & \multirow[t]{2}{*}{237} \\
\hline & & Antisense, 546:GCATAGCAACATTAGGTCTG GGAG ${ }^{a}$ & & Antisense, 408:CAGACATTAGAGGCGAGGGGT & \\
\hline \multirow[t]{2}{*}{ PV } & \multirow[t]{2}{*}{ NM13645.3 } & Sense, 104:GCCTGAGAAAAAGAACCCG & \multirow[t]{2}{*}{275} & Sense, 122:CGGATGAGGTGAAGAAGGTGT & \multirow[t]{2}{*}{163} \\
\hline & & Sense, 275:AATCTTGCCGTCCCCATCCT & & Antisense, 265:TCCCCATCCTTGTCTCCAGC & \\
\hline \multirow[t]{2}{*}{ GAD65 } & \multirow[t]{2}{*}{ NM008078.2 } & Sense, 99: CCAAAAGTTCACGGGCGG $^{a}$ & \multirow[t]{2}{*}{375} & Sense, 219: CACCTGCGACCAAAAAC CCT & \multirow[t]{2}{*}{248} \\
\hline & & Antisense, 454:TCCTCCAGATTTTGCGGTTG ${ }^{a}$ & & Antisense, 447:GATTTTGCGGTTGGTCTGCC & \\
\hline \multirow[t]{2}{*}{ GAD67 } & \multirow[t]{2}{*}{ NM008077.4 } & Sense, 83:ATGATACTTGGTGTGGCGTAGC ${ }^{a}$ & \multirow[t]{2}{*}{253} & Sense, 159:CAATAGCCTGGAAGAGAAGAGTCG & \multirow[t]{2}{*}{177} \\
\hline & & Antisense, 314:GTTTGCTCCTCCCCGTTCTTAG ${ }^{a}$ & & Antisense, 314:GTTTGCTCCTCCCCGTTCTTAG & \\
\hline
\end{tabular}

Note: Position 1, first base of start codon.

${ }^{a}$ From Karagiannis et al, 2009.
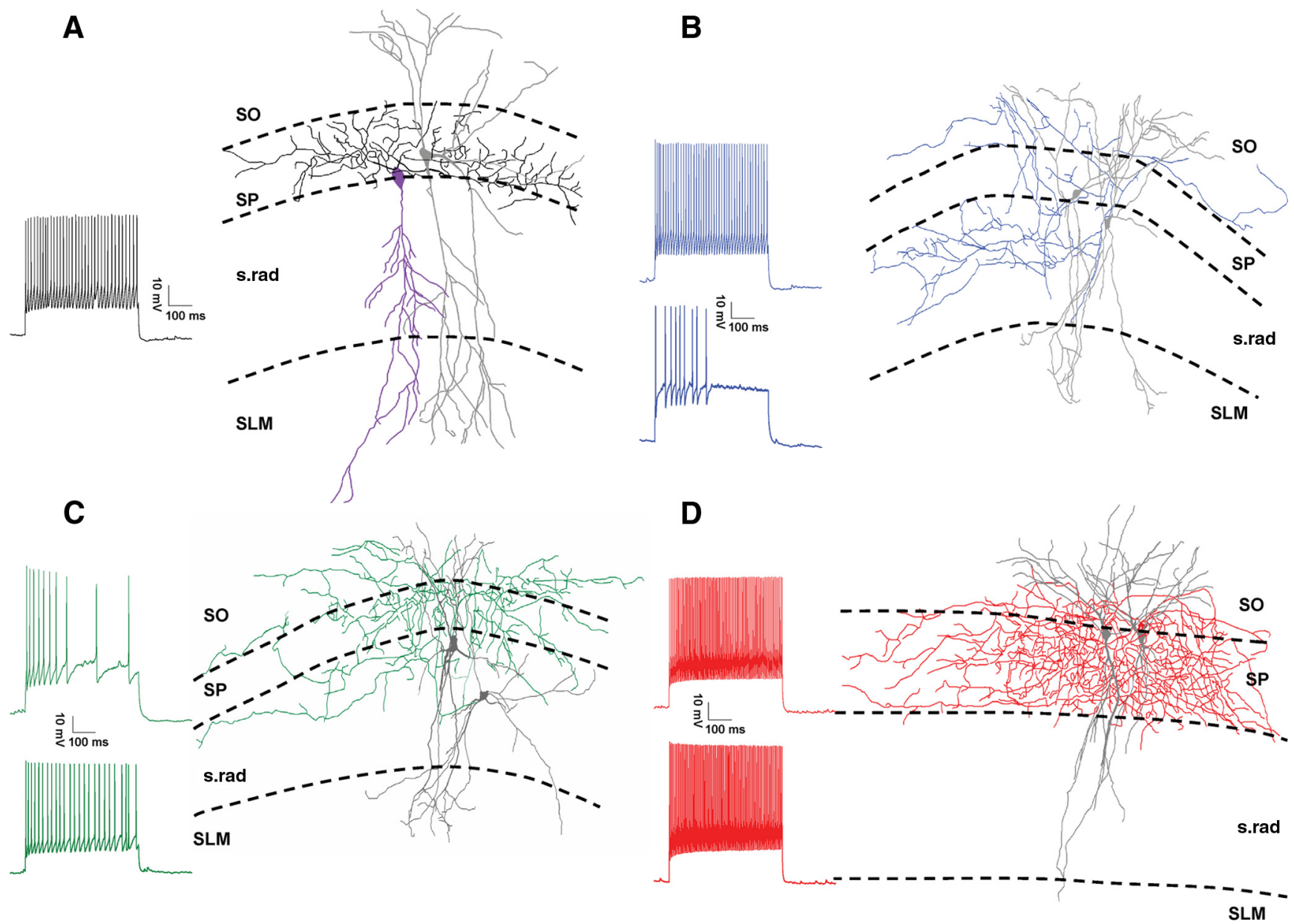

Figure 1. Four classes of interneuron. $A$, Reconstruction of a representative synaptically connected (CK basket cell to $P($ pair; $P($ soma and dendrites shown in purple (axon not recovered), basket cell dendrites and soma in gray, and axon in black. Trace shows responses to $500 \mathrm{~ms}$ depolarizing current of double action potential threshold amplitude in the CCKBC. B, Example bistratified cell pair; dendrites and soma shown in gray, axons in blue, presynaptic soma to the left. Traces show responses to a 500 ms depolarizing current of double action potential threshold amplitude; presynaptic upper, postsynaptic lower trace. C, Example trilaminar cell pair; dendrites and soma shown in gray, axons in green, presynaptic soma to the upper left. Traces are as in $\boldsymbol{B}$. D, Example PV basket cell pair; dendrites and soma shown in gray, axons in red, presynaptic soma right. Traces are as in $\boldsymbol{B}$. All cells illustrated are in CA1 and were reconstructed from a single section.

ferent domains of postsynaptic cells. However, it is unclear whether asynchronous release is confined to one inhibitory interneuron type within the dentate gyrus or is a more general principle that extends to other CCK-containing interneurons and all of their downstream targets within the hippocampus proper.

Here, we identify three morphologically distinct classes of putatively CCK-containing interneurons in the hippocampal CA fields, which, in contrast to the highly synchronous release from PV basket cells, show asynchrony of release onto both inhibitory and principal cells. We show that asynchronous release occurs in response to both high frequency bursts and to trains mimicking the natural firing activity of CCK-containing interneurons. Asynchronous release also reveals that quantal events are of surprisingly large variable amplitude.

\section{Materials and Methods}

Slice preparation. Hippocampal slices (300 $\mu \mathrm{m}$ thick) were prepared from mice aged postnatal day 12-22 (P12-22). All animals were anesthetized with isoflurane before decapitation according to National Institutes of Health animal welfare guidelines. C57BL/6, GAD-65 green fluorescent 
protein (GFP), or PV GFP mice were used as indicated (Brager et al., 2003). Brains were rapidly dissected out and placed in cold partial sucrose artificial CSF (aCSF) containing $80 \mathrm{~mm} \mathrm{NaCl}, 3.5 \mathrm{~mm} \mathrm{KCl}, 1.25 \mathrm{~mm} \mathrm{H}_{2} \mathrm{PO}_{4}, 25$ $\mathrm{mm} \mathrm{NaHCO}_{3}, 4.5 \mathrm{~mm} \mathrm{MgSO}_{4}, 0.5 \mathrm{~mm} \mathrm{CaCl}_{2}, 10$ $\mathrm{mm}$ glucose, and $90 \mathrm{~mm}$ sucrose equilibrated with 95\% $\mathrm{O}_{2} / 5 \% \mathrm{CO}_{2}$. Brains were hemisected and transverse sections were cut with a Leica VT1000S microtome. Slices were incubated at $35^{\circ} \mathrm{C}$ for $30 \mathrm{~min}$ and at least a further $30 \mathrm{~min}$ at room temperature $\left(\sim 22^{\circ} \mathrm{C}\right)$ in partial sucrose solution before recording.

Whole-cell recordings. Slices were transferred to a recording chamber and perfused with aCSF containing $125 \mathrm{~mm} \mathrm{NaCl}, 3.5 \mathrm{~mm} \mathrm{KCl}$, $1.25 \mathrm{~mm} \mathrm{H}_{2} \mathrm{PO}_{4}, 25 \mathrm{~mm} \mathrm{NaHCO}_{3}, 1.5 \mathrm{~mm}$ $\mathrm{MgSO}_{4}, 2.5 \mathrm{~mm} \mathrm{CaCl}_{2}$ (or as indicated), and 20 $\mathrm{mM}$ glucose, equilibrated with $95 \% \mathrm{O}_{2} / 5 \%$ $\mathrm{CO}_{2}$, and maintained at $33-35^{\circ} \mathrm{C}$. For strontium experiments, $\mathrm{CaCl}_{2}$ was replaced with 4 $\mathrm{mM} \mathrm{SrCl}_{2}$ and $1 \mathrm{~mm}$ EGTA. Cells were visualized using $40 \times$ objective and infrared differential interference contrast video microscopy (Zeiss Axioskop 2 FS Plus). Fluorescence of GFP-containing cells was excited by a Lamda LS light source (Sutter Instruments) and visualized online using Spot Basic imaging software and RT KE camera (both Diagnostic Instruments). Whole-cell recordings were made using a Multiclamp 700A amplifier (Molecular Devices). Recording electrodes (3-5 M $\Omega$ ) were filled with a solution containing $130 \mathrm{~mm} \mathrm{KCl}$, $8.5 \mathrm{~mm} \mathrm{NaCl}, 4$ mm MgATP, $0.3 \mathrm{~mm} \mathrm{Na}$ GTP, 5 mM HEPES, and $0.5 \mathrm{~mm}$ EGTA adjusted to $\mathrm{pH}$ 7.3 using $\mathrm{KOH}$ and $290 \mathrm{mOsm}$ using sucrose. Biocytin $(2 \mathrm{mg} / \mathrm{ml})$ was added on the day of recording. Uncompensated series resistance (8-25 $\mathrm{M} \Omega$ for interneurons, 5-20 $\mathrm{M} \Omega$ for pyramidal cells) was monitored in postsynaptic cells via a $-5 \mathrm{mV}$ voltage step, and recordings were stopped after changes $>30 \%$. Firing patterns were investigated by giving a series of incrementing $500 \mathrm{~ms}$ duration current steps from $-70 \mathrm{mV}$. Increments were between 20 and $150 \mathrm{pA}$, with the first step being of double the increment amplitude and the last step at least double action potential threshold amplitude. Presynaptic trains were induced using $252 \mathrm{~ms} 1-2 \mathrm{nA}$ current steps at $50 \mathrm{~Hz}$ from $-70 \mathrm{mV}$ while holding the postsynaptic cell at -70 $\mathrm{mV}$ in voltage clamp. Ten trains were delivered at $0.1 \mathrm{~Hz}$. During strontium experiments, trains were delivered at $0.05 \mathrm{~Hz}$. The effect of lowering $\left[\mathrm{Ca}^{2+}\right]_{\mathrm{E}}$ was monitored with a paired pulse paradigm of two $2 \mathrm{~ms}$ current steps at $50 \mathrm{~Hz}$ delivered every $10 \mathrm{~s}$. Depolarization-induced suppression of inhibition (DSI) was induced by depolarizing the postsynaptic cell to $0 \mathrm{mV}$ for $1 \mathrm{~s}$ before every fourth trial, using the same paired-pulse paradigm as above. DSI was calculated as the amplitude of the average of 10 IPSCs after depolarization as a percentage of the average of 10 IPSCs immediately preceding depolarization. Data were acquired at $10 \mathrm{kHz}$ using Pclamp 9.2 (Molecular Devices) and filtered at $4 \mathrm{kHz}$.

Data analysis. Trains were deconvolved as follows using IgorPro (Wavemetrics). An artificial miniature IPSC (mIPSC) was created using the rise to peak of a recorded unitary IPSC and a single exponential decay to baseline calculated from a fit of the IPSC to remove noise. Separate artificial mIPSCs were created for each pair analyzed based on the kinetics of the IPSCs recorded in that pair. This MIPSC was then scaled to give a peak of $20 \mathrm{pA}$. This value was chosen as close to the smallest events detected after the train in most cells. Baseline was subtracted from postsynaptic waveforms and 20 repetitions of binomial (Gaussian) smoothing were applied. Fourier transforms of the mIPSC and individual trains were calculated. The Fourier transform of the mIPSC was then divided, point by point, in to the Fourier transform of the train. The quotient of this division was

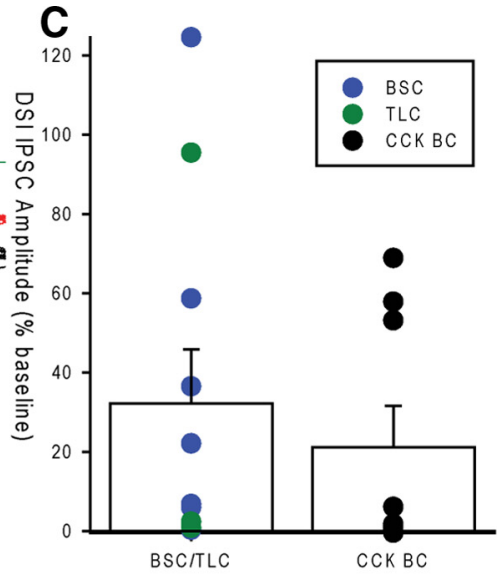

D

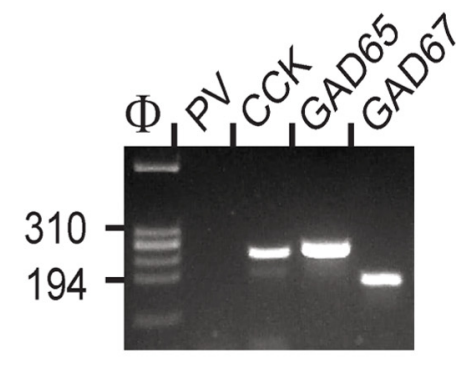

returned to the time domain via the inverse Fourier transform to produce the release rate histogram (Diamond and Jahr, 1995).

Synchronous release was calculated from the area under the release rate histogram for the $5 \mathrm{~ms}$ after the onset of the presynaptic current step, whereas asynchronous release was the area of the following $15 \mathrm{~ms}$ [i.e., until the start of the next current step (see Fig. $4 \mathrm{~A}$, bottom panel, and supplemental Fig. S1, available at www.jneurosci.org as supplemental material)] and, when calculating asynchronous release for the entire burst, for the period after the last step until the end of the trace. Asynchronous release after the end of the train was included only for data referring to the entire train. This method almost certainly underestimates the degree of asynchronous release (e.g., one third of truly random release would be regarded as synchronous) but does so equally across all cells and allows for jitter in spike timing and in the delay to the onset of the synchronous IPSC. For natural trains, the time window used to calculate asynchronous was from $5 \mathrm{~ms}$ after the start of one current pulse until the start of the next pulse in all cases. Both modes of release were calculated from an average of 10 release rate histograms each calculated from a single postsynaptic waveform. Synchronicity ratio (SR) was simply synchronous release/asynchronous release for the given time period.

Individual events in the release rate histogram were detected by threshold detection (Clampfit 9.2). Amplitude of the event was calculated from the area under the curve $0.5 \mathrm{~ms}$ either side of the peak. Asynchronous event amplitudes used to calculate distributions in Figure 7, F and $G$, were detected by template search also in Clampfit 9.2.

Statistical significance between four cell classes are results of single factor ANOVA. Significance values for amplitude distributions were results of Kolmogorov-Smirnov test. All other values of statistical significance are results of two-tailed $t$ tests. All statistics are shown \pm SEM. 
Table 2. Properties of synaptic transmission

\begin{tabular}{|c|c|c|c|c|c|c|c|c|c|c|c|c|c|c|c|c|c|c|}
\hline & \multicolumn{2}{|l|}{ Latency } & \multicolumn{2}{|l|}{ Latency SD } & \multicolumn{2}{|l|}{ Amplitude } & \multicolumn{2}{|l|}{ Rise time } & \multicolumn{2}{|l|}{ Decay } & \multicolumn{2}{|l|}{ PPR } & \multicolumn{2}{|l|}{ CV } & \multicolumn{2}{|l|}{ Failures } & \multicolumn{2}{|l|}{ CV (EF) } \\
\hline & $\mathrm{ms}$ & $n$ & $\mathrm{~ms}$ & $n$ & $\mathrm{pA}$ & $n$ & $\mathrm{~ms}$ & $n$ & $\mathrm{~ms}$ & $n$ & & $n$ & & $n$ & & $n$ & & $n$ \\
\hline \multicolumn{19}{|l|}{ IN to IN } \\
\hline$C C K B C$ & $1.26 \pm 0.24$ & 8 & $0.23 \pm 0.05$ & 8 & $89 \pm 29$ & 13 & $0.95 \pm 0.14$ & 13 & $4.49 \pm 0.55$ & 13 & $0.95 \pm 0.12$ & 13 & $0.73 \pm 0.09$ & 8 & $0.26 \pm 0.09$ & 8 & $0.49 \pm 0.05$ & \\
\hline BSC & $1.09 \pm 0.09$ & 23 & $0.24 \pm 0.04$ & 23 & $61 \pm 17$ & 48 & $0.92 \pm 0.07$ & 52 & $4.99 \pm 0.32$ & 52 & $1.07 \pm 0.08$ & 48 & $1.28 \pm 0.09$ & 26 & $0.55 \pm 0.05$ & 26 & $0.55 \pm 0.05$ & 26 \\
\hline TLC & $1.43 \pm 0.28$ & 7 & $0.23 \pm 0.03$ & 7 & $64 \pm 27$ & 6 & $0.71 \pm 0.10$ & 7 & $3.84 \pm 0.59$ & 7 & $1.06 \pm 0.13$ & 6 & $1.20 \pm 0.21$ & 4 & $0.46 \pm 0.11$ & 4 & $0.63 \pm 0.13$ & \\
\hline PVBC & $0.6 \pm 0.07$ & 8 & $0.07 \pm 0.01$ & 8 & $328 \pm 92$ & 9 & $0.63 \pm 0.06$ & 11 & $2.67 \pm 0.13$ & 11 & $0.65 \pm 0.06$ & 9 & $0.22 \pm 0.02$ & 7 & $0.00 \pm 0.00$ & 7 & $0.22 \pm 0.02$ & \\
\hline \multicolumn{19}{|l|}{ IN to $P C$} \\
\hline CCKBC & $0.78 \pm 0.08$ & 23 & $0.15 \pm 0.02$ & 23 & $316 \pm 78$ & 29 & $0.86 \pm 0.11$ & 32 & $6.68 \pm 0.34$ & 32 & $0.77 \pm 0.03$ & 29 & $0.54 \pm 0.07$ & 20 & $0.16 \pm 0.04$ & 20 & $0.38 \pm 0.04$ & 20 \\
\hline BSC & $1.08 \pm 0.15$ & 16 & $0.18 \pm 0.02$ & 16 & $184 \pm 64$ & 21 & $1.05 \pm 0.14$ & 30 & $6.81 \pm 0.42$ & 28 & $0.83 \pm 0.08$ & 21 & $0.84 \pm 0.14$ & 12 & $0.25 \pm 0.09$ & 12 & $0.51 \pm 0.06$ & 12 \\
\hline TLC & $1.05 \pm 0.17$ & 8 & $0.22 \pm 0.06$ & 8 & $158 \pm 62$ & 13 & $1.23 \pm 0.29$ & 13 & $7.75 \pm 0.91$ & 12 & $0.72 \pm 0.06$ & 12 & $0.82 \pm 0.10$ & 6 & $0.30 \pm 0.06$ & 6 & $0.48 \pm 0.07$ & \\
\hline PVBC & $0.49 \pm 0.05$ & 12 & $0.07 \pm 0.01$ & 12 & $308 \pm 62$ & 18 & $0.65 \pm 0.12$ & 18 & $5.94 \pm 0.47$ & 17 & $0.50 \pm 0.03$ & 18 & $0.28 \pm 0.04$ & 12 & $0.01 \pm 0.01$ & 12 & $0.27 \pm 0.03$ & 12 \\
\hline
\end{tabular}

All statistics based on the response to the first of two presynaptic spikes (except PPR) delivered every 10 s, calculated from 30 trials, and categorized by presynaptic interneuron class for interneuron to interneuron (IN to IN) and interneuron to PC (IN to PC) pairs. Latency is average onset latency relative to peak of presynaptic spike; latency SD is the SD of onset latency (jitter). Rise time is $10-90 \%$ rise of average IPSC. Decay $\tau$ was calculated from a single exponential fit of average IPSC. PPR is a ratio of peak amplitude of second IPSC to that of first IPSC. CV is coefficient of variation of peak amplitude (EF, excluding failures).

Single-cell reverse transcription-PCR. At the end of a subset of recordings, cytoplasm was aspirated into the recording pipette while in wholecell configuration. The pipette was removed to allow outside-out patch formation. The content of the pipette was then expelled into a test tube, and reverse transcription (RT) was performed at a final volume of $10 \mu \mathrm{l}$ as described previously (Lambolez et al., 1992). Slices were then fixed overnight at $4^{\circ} \mathrm{C}$ in $4 \%$ paraformaldehyde in PBS (0.1 M) for subsequent biocytin staining (see below).

The single-cell reverse transcription-PCR (scRT-PCR) protocol was designed to detect simultaneously the expression of CCK, PV, and the two isoforms of glutamic acid decarboxylase (GAD65 and GAD67). Two steps of PCR were performed as described previously (Cauli et al., 1997). The cDNA present in $10 \mu \mathrm{l}$ of the RT reaction were first amplified simultaneously by using all the primer pairs described in Table 1 (for each primer pair, the sense and antisense primers were positioned on two different exons). Taq polymerase (2.5 U; Qiagen $\mathrm{GmbH}$ ) and $20 \mathrm{pmol}$ of each primer were added to the buffer supplied by the manufacturer (final volume, $100 \mu \mathrm{l}$ ), and $21 \mathrm{cycles}\left(94^{\circ} \mathrm{C}\right.$ for $30 \mathrm{~s}, 60^{\circ} \mathrm{C}$ for $30 \mathrm{~s}$, and $72^{\circ} \mathrm{C}$ for $30 \mathrm{~s}$ ) of PCR were run. Second rounds of PCR were performed using $2 \mu \mathrm{l}$ of the first PCR product as a template. In the second round, each cDNA was amplified individually with a second set of primer pair internal to the primer pair used in the first round (Table 1, nested primers) and positioned on two different exons. Thirty-five PCR cycles were performed (as described above). Then, $10 \mu \mathrm{l}$ of each individual PCR were run on a $2 \%$ agarose gel, with $\Phi$ X174 digested by HaeIII as a molecular weight marker and stained with ethidium bromide. The RT-PCR protocol was tested on $100 \mathrm{pg}$ of total RNA purified from mouse whole brain. All the transcripts were detected from 100 pg of whole-brain RNA (data not shown). The sizes of the PCR-generated fragments were as predicted by the mRNA sequences (Table 1). Control experiments for mRNA contamination from surrounding tissue were performed by placing a patch pipette in the slice without establishing a seal. Positive pressure was then interrupted, and, after the removal of the pipette, its content was processed as described. No PCR product was obtained using this protocol $(n=6)$. Positive controls for detection of PV expression in a fast-spiking (FS) interneuron and in whole brain are shown in supplemental Fig. S2, available at www.jneurosci.org as supplemental material.

Anatomical reconstruction. After biocytin filling during whole-cell recordings, slices were fixed with $4 \%$ paraformaldehyde and stored at $4^{\circ} \mathrm{C}$, then permeabilized with $0.3 \%$ Triton X-100 and incubated with Alexa 555 or Alexa 633-conjugate avidin. Resectioned slices were mounted on gelatin-coated slides using Mowiol mounting medium. Cells were visualized using epifluorescence microscopy (Olympus AX70), imaged using confocal microscopy (Leica TCS SP2RS or Zeiss Live Duoscan), and reconstructed using Neurolucida (MicroBrightField).

\section{Results}

\section{Identification of interneuronal classes}

To test whether highly asynchronous release occurs in multiple CCK-containing interneuron classes, we made whole-cell recordings from synaptically connected interneuron-interneuron
A

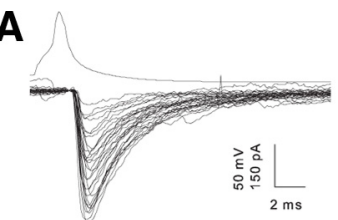

B

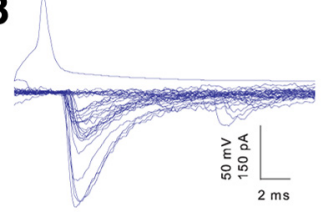

C

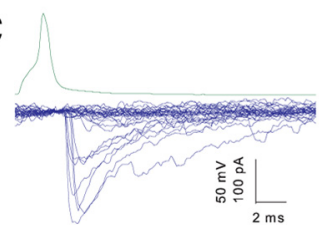

D

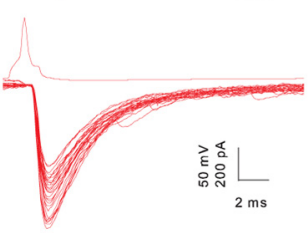

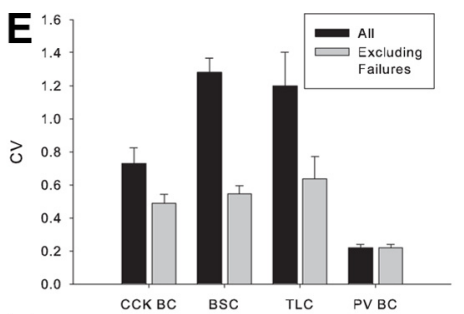

$F^{\circ}$

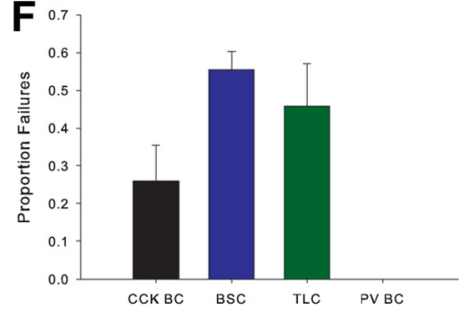

G

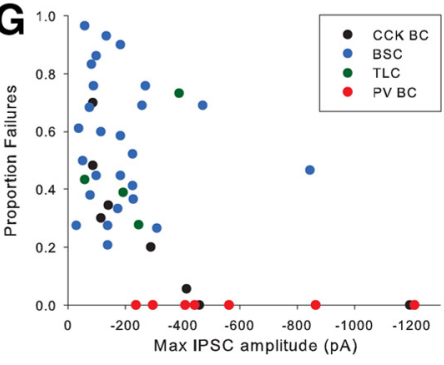

Figure 3. Properties of synaptic transmission at interneuron to interneuron synapses. $A$, Example $C A 1$ CCK BC to CCK BC recording. Lower trace shows voltage response to a single presynaptic spike in postsynaptic cell in 30 trials. $B$, Example CA3 BSC to BSC pair. $C$, Example CA1 TLC to BSC pair. D, Example CA1 PV BC to PV BC pair. E, Histogram showing average coefficient of variation (CV) of IPSC amplitude including ( $p<5 \times 10^{-7}$, single factor ANOVA) and excluding $(p<0.005)$ failures for 4 classes of presynaptic interneuron. $\boldsymbol{F}$, Histogram showing proportion of failures of transmission for 4 interneuron classes $\left(p<5 \times 10^{-6}\right)$. $G$, Amplitude of largest IPSC amplitude from 30 trials versus proportion of failures for individual pairs categorized by presynaptic cell type.

or interneuron-pyramidal cell pairs in the CA1 and CA3 regions of the hippocampus. No significant differences $(p \geq 0.2)$ were found between any properties of recordings made in CA1 and CA3, so data were pooled. Physiological properties of cells were tested with a series of incrementing current steps (500 ms duration). Presumed CCK interneuron recordings were made from GFP positive cells in a mouse line expressing enhanced GFP (EGFP) under a GAD-65 promoter (Brager et al., 2003). EGFP in this mouse line labels many CCK-containing cells but few, if any, PV-containing cells in cortex (López-Bendito et al., 2004; Zhang 

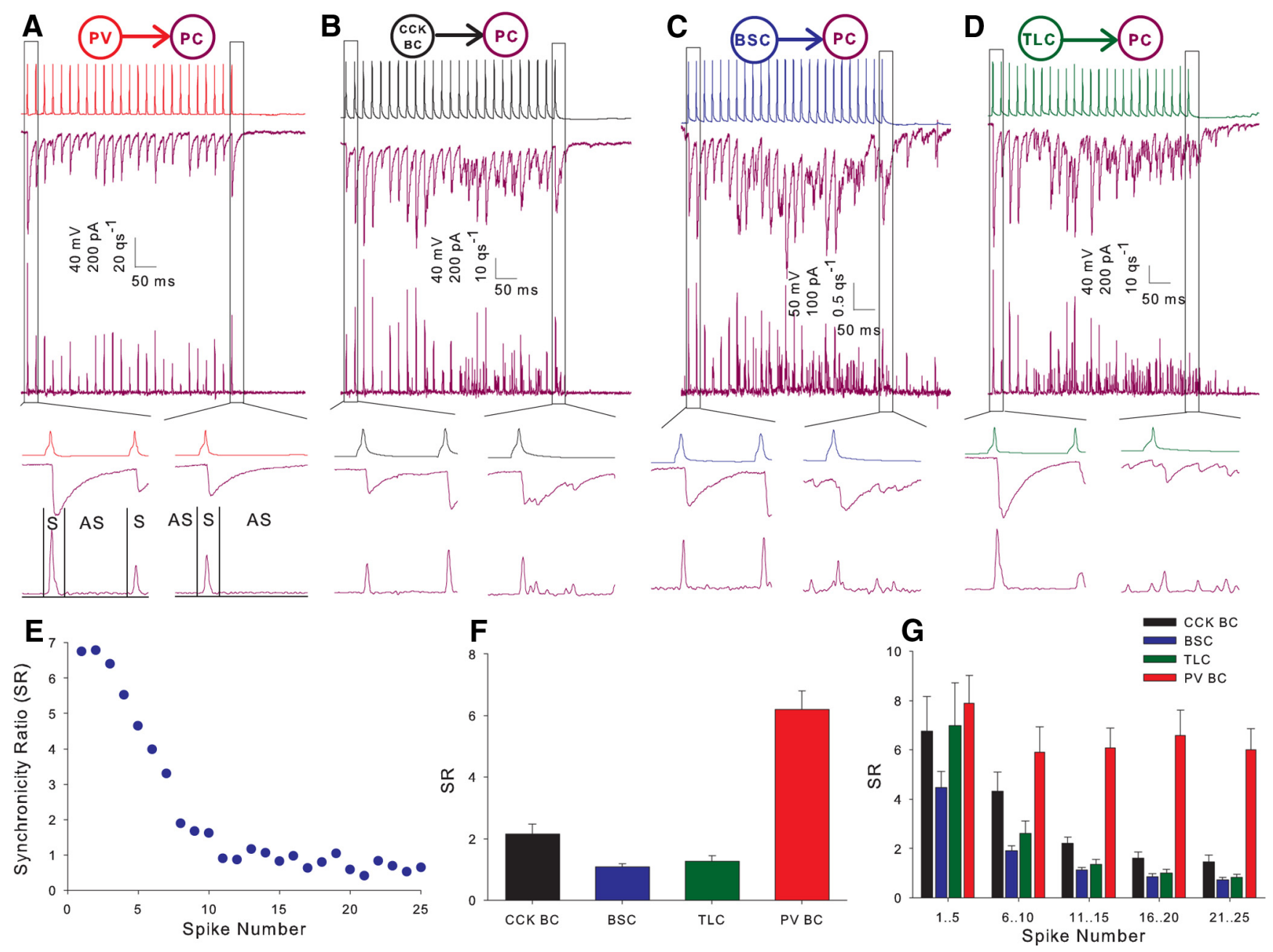

Figure 4. Interneuron cell classes display different proportions of asynchronous release onto postsynaptic pyramidal cells. $A$, Example recording showing the postsynaptic response in a pyramidal cell (purple here and throughout figures) to a train of action potentials in a PV BC (red throughout). Middle trace shows voltage clamp recording at $-70 \mathrm{mV}$; lower trace shows the corresponding deconvolved release rate histogram. Lower inserts show expanded time course for 1st (left) and 25th (right) action potentials. Box marked $S$ represents 5 ms used to calculate synchronous release; box marked AS represents 15 ms for asynchronous release. qs ${ }^{-1}$, Quanta per second. B, Example CCKBC (black throughout) to pyramidal cell pair arranged as in $A$. C, Example BSC (blue throughout) to pyramidal cell pair. D, Example TLC (green throughout) to pyramidal cell pair. $\boldsymbol{E}$, SR versus spike number plot for example recording shown in $\boldsymbol{C}$. Data calculated from average of 10 sweeps. $\boldsymbol{F}$, Full train SR versus interneuron class histogram for all interneuron to pyramidal cell pairs. CCKBC $n=28$ (CA1 $n=26, \mathrm{CA} 3 n=2), \mathrm{BSC} n=30$ (CA1 $n=27, \mathrm{CA} 3 n=3), \mathrm{TLC} n=20$ (CA1 $n=19, \mathrm{CA} 3$ $n=1$ ), $\mathrm{PV} \mathrm{BC} n=12$ (all CA1); $p<5 \times 10^{-19}$. G, Histogram plotting SR against grouped spikes throughout the train for all interneuron to pyramidal cell pairs. Spikes $1-5 p=0.2,6-10 p<$ $0.0005,11-15 p<10^{-16}, 16-20 p<5 \times 10^{-18}, 21-25 p<5 \times 10^{-19}$.

et al., 2006) a finding which we have confirmed in the hippocampus (supplemental Figs. S3, S4, available at www.jneurosci.org as supplemental material). These interneurons had somata located in stratum pyramidale (SP), stratum lucidum, or the inner third of stratum radiatum (s.rad) closest to the cell layer with radially orientated dendrites crossing all layers from stratum oriens ( $\mathrm{SO}$ ) to stratum lacunosum moleculare (SLM). Although many cell types express GFP in this mouse line, we focused on interneurons comprised of three axonal morphological classes: basket cells (BCs) with axon restricted to SP (Fig. 1A), bistratified cells (BSCs) with axon located primarily in s.rad and $\mathrm{SO}$ (Fig. $1 B$ ), and trilaminar cells (TLCs) with axon evenly distributed between SO, SP, and s.rad (Fig. 1C). All GAD-65 BC-pyramidal cell (PC) pairs tested showed pronounced depolarization-induced suppression of inhibition (DSI: defined as $>30 \%$ suppression) (IPSC $21 \pm 10 \%$ baseline, $n=9, p<0.00005$ ) (Fig. $2 B$ ), which, together with the lack of FS characteristics, confirms that these BCs correspond to CCK BCs (Pitler and Alger, 1992; Katona et al., 1999; Wilson et al., 2001; Földy et al., 2007) and will be referred to as such throughout. For presynaptic BSCs and TLCs to PC pairs, 9 of 11 pairs tested showed DSI $(32 \pm 14 \%$ baseline, $p<0.005)$ consistent with the assumption that these cells are also CCK-containing. Additionally, we performed scRT-PCR on a subset of recorded cells. The majority of all non-FS cell types tested positive for the presence of CCK mRNA (7/10 CCK BCs, 7/12 BSCs, and 6/9 TLCs) (Fig. 2C,D). These findings confirm that GFP-labeled, non-FS interneurons exhibiting the axonal morphology of CCK BCs, BSCs, and TLCs are CCK containing.

For comparison, recordings were made from PV-containing interneurons. These cells were identified using a mouse line expressing EGFP under a PV promoter (B13 line) (Goldberg et al., 2008) or by their firing properties, and confirmed morphology in wild-type mice or non-GFP positive cells in GAD65-GFP mice. PV-containing interneurons were typified by a FS phenotype comprising narrow action potentials with deep, brief after hyperpolarization (AHP) and a lack of spike frequency adaptation (Fig. 1D) (Kawaguchi et al., 1987). Average action potential frequency throughout $500 \mathrm{~ms}$ current step at double threshold current amplitude was $108 \pm 20 \mathrm{~Hz}$ ( $28 \pm 1 \mathrm{~Hz}$ for non-FS cells). All FS cells had BC morphology (Fig. 

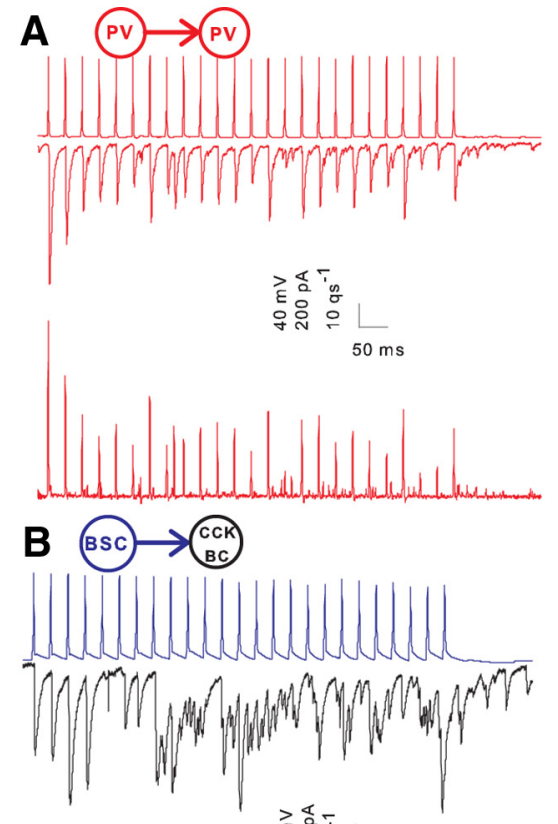

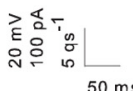
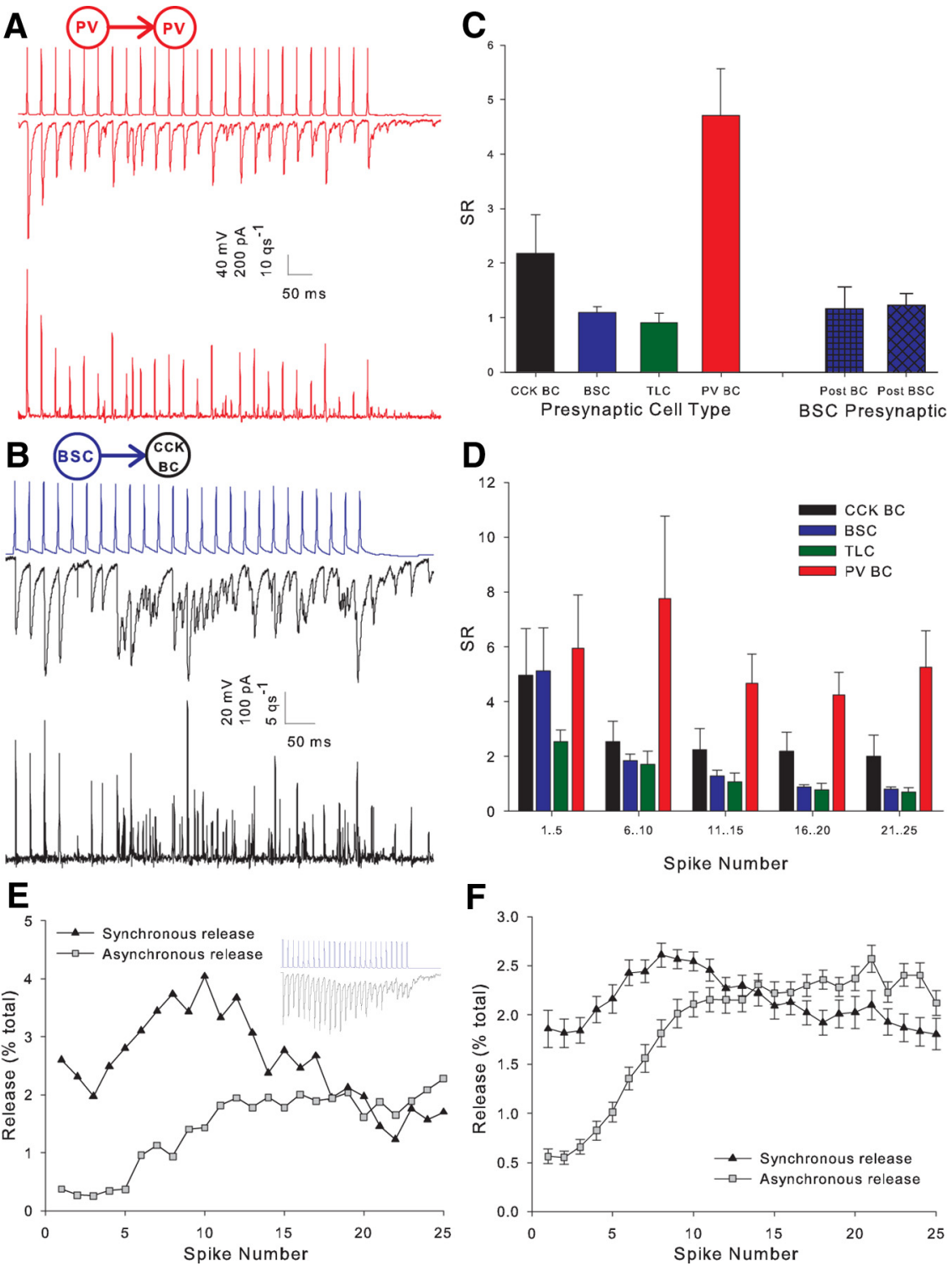

Figure 5. Degree of asynchrony is determined by the presynaptic cell type. $\boldsymbol{A}$, Example PV BC to PV BC pair. $\boldsymbol{B}$, Example BSC to CCK BC pair. C, Full train SR versus interneuron class histogram for all interneuron to interneuron cell pairs. Four left bars show pairs categorized according to presynaptic cell type. Two right bars show pairs with presynaptic BSC categorized according to postsynaptic cell type. Presynaptic CCKBC $n=9$ (CA1 $n=6$, CA3 $n=3)$, presynaptic BSC $n=39$ (CA1 $n=34$, CA3 $n=5$; postsynaptic CCKBC $n=7$, postsynaptic BSC $n=10)$, presynaptic $\operatorname{TLC} n=9($ CA1 $n=7$, CA3 $n=2)$, presynaptic PV BC $n=8$ (all CA1); $p<$ $1 \times 10^{-9}$. D, Histogram plotting SR against grouped spikes throughout the train for all interneuron to interneuron pairs categorized by presynaptic cell type. Spikes $1-5 p=0.9,6-10 p<0.0001,11-15 p<5 \times 10^{-5}, 16-20 p<5 \times 10^{-9}, 21-25 p<$ $5 \times 10^{-9}$. , Time plot showing the percentage of the total release throughout an example train (shown in inset) for each action potential in the train. Synchronous release is shown by triangles and asynchronous release by squares. $\boldsymbol{F}$, Mean release versus time plot for all non-PV interneuron to interneuron recordings $n=57$.

1D). Because of the FS phenotype and PV-GFP expression in a subset of cells, these interneurons will be referred to as PV BCs.

CCK-containing interneurons produce highly variable IPSCs We made paired recordings from interneuron-interneuron and interneuron-PC pairs. Synaptic connections were identified in 326/1521 (21\%) GAD65-GFP to GAD65-GFP pairs, 168/825 (20\%) GAD-65 GFP to PC pairs, 24/29 (82\%) FS to FS pairs, and $38 / 82$ (46\%) FS to PC pairs. We did not systematically test for electrical coupling, but spikelets were very rarely seen in postsynaptic cells except in PV BC to PV BC pairs. We analyzed the properties of synaptic transmission by inducing pairs of action potentials separated by $20 \mathrm{~ms}$ in the presynaptic cell every $10 \mathrm{~s}$ while holding the postsynaptic cell at $-70 \mathrm{mV}$ in voltage clamp; the results are shown in Table 2. A striking property of transmission from CCK interneurons, especially BSCs and TLCs, is the large variability both in onset latency (Table 2; Fig. $3 A-D$ ) and peak amplitude (Table 2; Fig. $3 A-G$ ) of IPSCs. In part, the variability in BSC and TLC IPSC amplitude was attributable to a high proportion of failures (Fig. $3 B, C, F$ ); however, even when failures were excluded from analysis variability was still high. In comparison, latency and amplitude of PV BC IPSCs were very consistent with almost no failures (Fig. 3D-F); in fact only 1 of 29 pairs with a presynaptic PV BC showed any failures of transmission in 30 trials. One explanation for the difference in proportion of failures may be a larger number of release sites mediating transmission from BCs (as indicated by higher average peak amplitude); however, even TLCs and BSCs capable of producing large IPSCs show a larger proportion of failures (Fig. 3G).

\section{Synchrony of release onto pyramidal cells corresponds to interneuron class} We tested the response of pairs to trains of 25 action potentials at $50 \mathrm{~Hz}$ in the presynaptic cell. As in the dentate gyrus (Hefft and Jonas, 2005), the postsynaptic response to the train in PV BCs was a train of IPSCs, which remained highly synchronous throughout (Fig. 4A, middle trace). In contrast, while initially synchronous the responses to CCK BCs (Fig. 4B, middle trace), BSCs (Fig. 4C, middle trace) and TLCs (Fig. 4D, middle trace) became desynchronized later in the train. To quantify the level of synchrony in the release process, postsynaptic responses were deconvolved with a simulated mIPSC. The simulated mISPC consisted of the rise and peak of the unitary IPSC and a single exponential fit to the decay of the same IPSC. This was then scaled to a peak amplitude of $20 \mathrm{pA}$; close to the amplitude of smallest observed events. This method allows an estimate of the number and timing of release of individual quanta of transmitter (Diamond and Jahr, 1995). The resulting release rate histograms are shown for individual examples in Figures $4 A-D$ (lower traces). The ratio of synchronous to asynchronous release (SR) (see Materials and Methods) was then calculated for each presynaptic action potential (Fig. $4 E$, corresponding to the pair in $4 C$ ) and for the entire train (Fig. $4 F$ ). Higher values of SR represent more synchronous release. SR for the entire train was greatest for PV BCs (6.2 \pm 0.6 , $n=12$ ) (Fig. $4 A, F)$ followed by CCK BCs $(2.1 \pm 0.3, n=28$ ) (Fig. $4 B, F)$, TLCs $(1.3 \pm 0.2, n=20)$ (Fig. $4 D, F)$, and the greatest asynchrony was observed in BSCs $(1.1 \pm 0.1, n=30$ ) (Fig. $4 C, F$ ) (all groups, $p<5 \times 10^{-16}$, one-factor ANOVA). Separating the train 
into groups of 5 consecutive action potentials (Fig. 4G) reveals that there is little difference between cell types at the start of the train with release being highly synchronous from all cell types. In the three nonfast spiking classes, however, SR rapidly declines throughout the train.

\section{Asynchronous release is determined by presynaptic cell type}

We have shown that the synchrony of release onto pyramidal cells depends on interneuron class however presynaptic properties often depend on target cell identity (Pelkey and McBain, 2007). To establish whether the high level of asynchronous release is unique to interneuronprincipal cell synapses we made recordings from synaptically connected pairs of interneurons. All PV BCs were recorded in pairs with other PV BCs, whereas all combinations of the three CCK-containing classes were recorded. In all recordings postsynaptic cells were GFP-positive interneurons.

Again, PV BC pairs showed the most synchronous release throughout the entire train ( $\mathrm{SR}=4.7 \pm 0.9, n=8$ ) (Fig. $5 A, C)$ followed by pairs in which CCK $\mathrm{BCs}$ were presynaptic to other CCK interneurons $(2.2 \pm 0.7, n=9)$ (Fig. $5 C$ ). Presynaptic BSCs $(1.1 \pm 0.1, n=39)$ (Fig. $5 B, C)$ and TLCs $(1.0 \pm 0.2, n=9)$ (Fig. $5 C$ ) (all groups, $p<5 \times 10^{-9}$ ) showed the lowest degree of synchrony of release. Morphology was recovered for $\sim 50 \%$ of postsynaptic cells and was consistent with those cell classes recorded presynaptically (CCK BC $n=10, \operatorname{BSC} n=13$ and TLC $n=$ 4) (Fig. 1). In recordings where BSCs were presynaptic, there was no difference in the synchronicity ratio when the postsynaptic cell was either a CCK BC $(1.2 \pm 0.4, n=7)$ (Fig. $5 C)$ or a BSC $(1.2 \pm 0.2, n=10, p=$ $0.9)$ (Fig. $5 C$ ). The number of pairs where anatomy was recovered for both the presynaptic and postsynaptic cell did not allow this comparison for presynaptic CCK BCs or TLCs.

Importantly, no value of SR was significantly different from that seen in the respective interneuron-PC pairs, and the time course of SR throughout the trains closely resembled that seen in postsynaptic PCs (Figs. $4 G, 5 D$ ). Figure 5, $E$ and $F$, an average of all non-FS interneuron-interneuron pairs, shows that the decrease in SR early in the train is due primarily to the rapid onset of asynchronous release, whereas the further decrease in SR later in the train is caused both a decrease in synchronous release and a further increase in asynchronous release. Together, these data show that the degree of asynchronous release is dictated solely by the identity of the presynaptic cell rather than a postsynaptic factor.

\section{Calcium dependence of synchronous and asynchronous release}

The calcium dependence of synchronous and asynchronous release and the implications of this for their respective mechanisms has been a focus of interest and contention (Goda and Stevens, 1994; Sun et al., 2007). The unusually large amount of asynchronous release at CCK interneuron synapses makes them particularly suitable for the study of these mechanisms.

In pairs exhibiting marked asynchrony ( $S R<2.5$ for all pairs), after the control period of 10 trains, we altered the extracellular $\mathrm{Ca}^{2+}$ concentration $\left(\left[\mathrm{Ca}^{2+}\right]_{\mathrm{E}}\right.$ ) (from $2.5 \mathrm{~mm}$ to 4,2 or $1.5 \mathrm{mM}$ ) while monitoring the effect on IPSC amplitude. As expected, an increase in $\left[\mathrm{Ca}^{2+}\right]_{\mathrm{E}}$ to $4 \mathrm{mM}$ caused an increase in IPSC amplitude (first IPSC $184 \pm 90 \%$ baseline, $n=6$, data not shown). A small but consistent decrease in SR was seen when $50 \mathrm{~Hz}$ trains were delivered in the presence of $4 \mathrm{mM} \mathrm{Ca}^{2+}$ (SR $79 \pm 6 \%$ of baseline, $n=6, p<0.05$ paired $t$ test) (Fig. $6 A, B, E)$. Decreasing $\left[\mathrm{Ca}^{2+}\right]_{\mathrm{E}}$ to $1.5 \mathrm{~mm}$ caused a decrease in IPSC amplitude $(1.5 \mathrm{~mm}$ $\mathrm{Ca}^{2+}$ :first IPSC $27 \pm 5 \%$ baseline, $\left.n=5, p<5 \times 10^{-5}\right)$ and $\mathrm{a}$ trend to an increase in SR, which did not reach significance (SR $119 \pm 18 \%$ baseline, $n=5, p=0.3$ ) (Fig. $6 C-E$ ). We fit these SR change data, together with further experiments reducing $\left[\mathrm{Ca}^{2+}\right]_{\mathrm{E}}$ to $2 \mathrm{mM}$, to a variety of functions. All functions assuming no change in SR $<2.5 \mathrm{~mm}$ produced a very poor fit (e.g., single exponential fit $R^{2}=0.07$ ), whereas a linear fit had an $R^{2}$ value of 

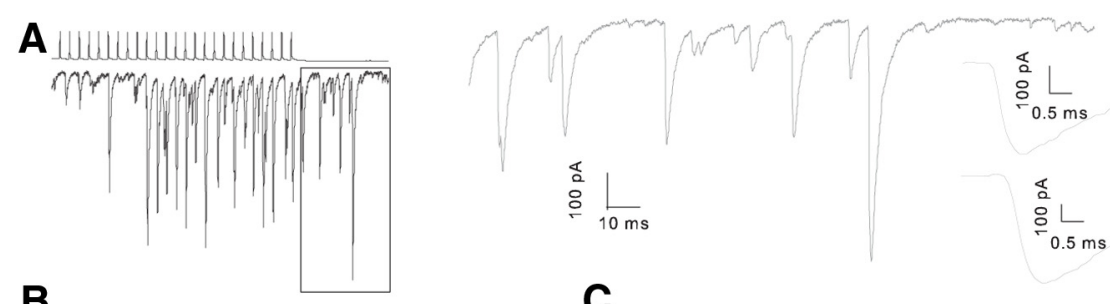

B

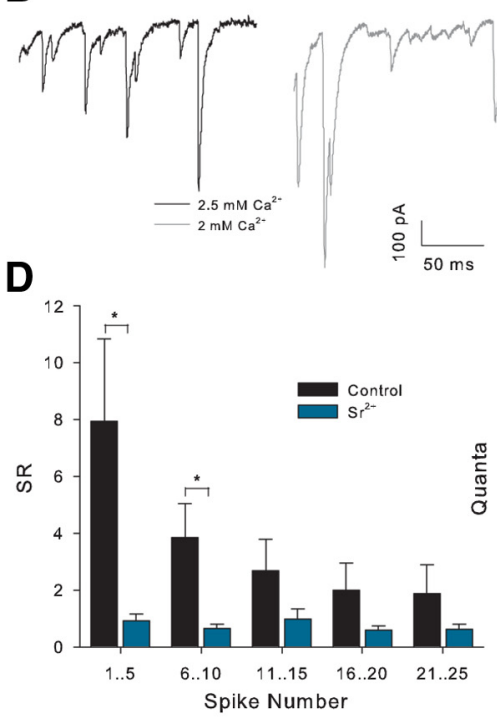

F

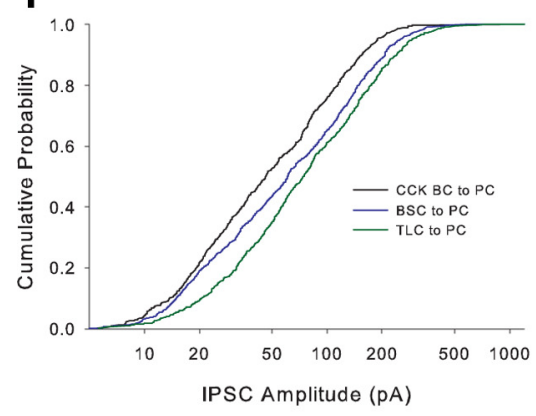

C
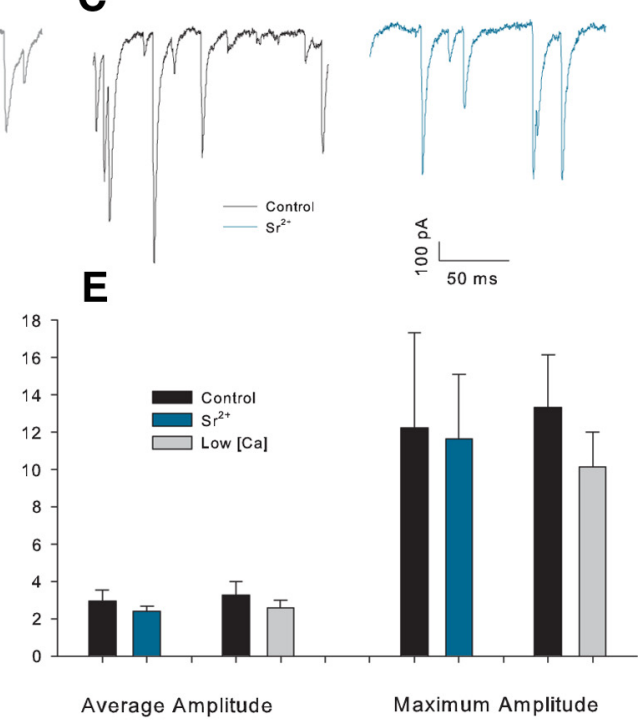

G

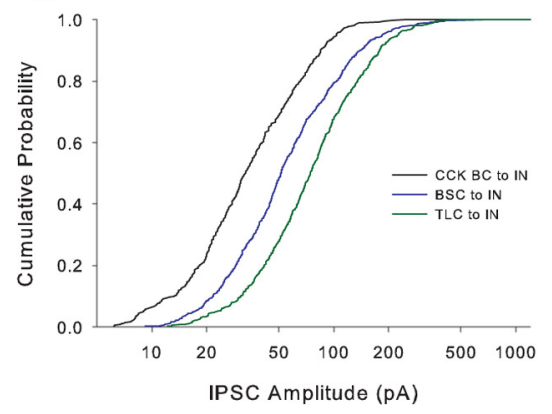

Figure 7. Large amplitude posttrain events persist in $\mathrm{Sr}^{2+}$ or low $\mathrm{Ca}^{2+}$. $\boldsymbol{A}$, Example recording showing large amplitude, apparently quantal, events. Trace on the right shows the boxed region on an expanded scale with the two largest amplitude events inset on far right with scale further expanded. $\boldsymbol{B}$, Example posttrain traces in $2.5 \mathrm{~mm} \mathrm{Ca}^{2+}$ (black) and $\mathrm{Sr}^{2+}$ (gray) in the same recording. $\boldsymbol{C}$, Example posttrain traces in control (black) and $\mathrm{Sr}^{2+}$ (turquoise) in the same recording. $\boldsymbol{D}$, Histogram of SR versus grouped spikes for all recordings in control and a solution comprising $4 \mathrm{~mm} \mathrm{Sr}^{2+}, 0 \mathrm{~mm} \mathrm{Ca}{ }^{2+}$, and $1 \mathrm{~mm} \mathrm{EGTA}\left(\mathrm{Sr}^{2+}\right), n=8(\mathrm{CA} 1$ $n=5$, CA3 $n=3) .{ }^{*} p<0.05$. E, Posttrain event amplitude histogram in control conditions low $\left[\mathrm{Ca}^{2+}\right]_{\mathrm{E}}$ and Sr${ }^{2+}$. Maximum amplitude is the mean value of the largest individual posttrain event in 10 sweeps for each condition. $\boldsymbol{F}$, Cumulative frequency amplitude distribution for posttrain asynchronous events in interneuron to $\mathrm{PC}$ pairs. CCK $n=9$ pairs (all CA1), BSC $n=9$ (all CA1), TLC $n=9$ (all CA1); $p<0.001$ for comparisons between all pairs cell types, Kolmogorov-Smirnov test. $G$, Cumulative frequency amplitude distribution for posttrain asynchronous events in interneuron to interneuron pairs categorized by presynaptic cell type. CCK BC $n=6$ (CA1 $n=5$, CA3 $n=1)$, BSC $n=9$ (CA1 $n=8$, CA3 $n=1)$, TLC $n=7$ (CA1 $n=5$, CA3 $n=2) ; p<0.001$ for comparisons between all pairs of cell types.

0.43. This suggests that the trend to increasing $\mathrm{SR}<2.5 \mathrm{~mm}$ $\left[\mathrm{Ca}^{2+}\right]_{\mathrm{E}}$ represents a genuine pattern.

\section{Large and variable quantal amplitude}

A prominent feature of the asynchronous barrage of ISPCs produced by the train of action potentials is the very large amplitude of some events. Figure $7 A$ shows a typical example where the largest apparently single events are $>500 \mathrm{pA}$ in peak amplitude equivalent to a conductance of $>7 \mathrm{nS}$. This amplitude is much larger than mean values of mIPSCs $(30-60 \mathrm{pA}$ equivalent to 0.4-0.8 nS) (Poncer et al., 1995; Thompson et al., 1997; Aponte

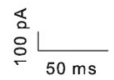

et al., 2006) and presumed quantal IPSCs (129 pA equivalent to $1.7 \mathrm{nS}$ ) (Kraushaar and Jonas, 2000) previously reported in the hippocampus. Three possible explanations exist for such large events: (1) uncoordinated but near-simultaneous quantal release events appear to be a single event; (2) asynchronous release has some synchronous component which is delayed from the action potential; and (3) a subset of release sites mediate very large conductance events.

Lowering $\left[\mathrm{Ca}^{2+}\right]_{\mathrm{E}}$ would be expected to distinguish the first possibility by lowering release probability and, therefore, separating individual events. To study only "asynchronous" release we analyzed the portion of the train after the final action potential. Analysis was performed on the deconvolved traces to temporally separate events. Lowering $\left[\mathrm{Ca}^{2+}\right]_{\mathrm{E}}$ had no effect on the amplitude of the largest individual events in each condition (baseline: $13.3 \pm$ 2.9 quanta, low $\left[\mathrm{Ca}^{2+}\right]_{\mathrm{E}}: 10.1 \pm 1.9$ quanta, $n=10, p=0.2)($ Fig. $7 B, E)$ indicating that summation of coincident events is unlikely to explain the large amplitude.

Lowering $\left[\mathrm{Ca}^{2+}\right]_{\mathrm{E}}$ would also be expected to decrease the amplitude of synchronous release delayed from the action potential but to further test for the second possibility we replaced extracellular $\mathrm{Ca}^{2+}$ with $\mathrm{Sr}^{2+}$ which desynchronizes release at central synapses (Goda and Stevens, 1994). This would be expected to remove any remaining synchrony among these delayed events. As expected, $\mathrm{Sr}^{2+}$ desynchronized release throughout the train (Fig. 7D) but caused no change in the amplitude of the largest events $\left(\mathrm{Ca}^{2+} 12.2 \pm 5.1\right.$ quanta, $\mathrm{Sr}^{2+} 11.6 \pm 3.4$ quanta, $n=6, p=0.8$ ) (Fig. $7 C, E)$. The example traces in Figure $5 C$ also show large $(\sim 300 \mathrm{pA}, 4 \mathrm{nS})$ events in the absence of a high frequency of smaller events confirming that summation of small events is an unlikely explanation. Similar results were produced when detection of IPSCs was performed on the original traces (data not shown). These data indicate that the most likely explanation is that a subset of very large amplitude quantal events are triggered by asynchronous release at CCKcontaining interneurons.

We also analyzed the amplitude distribution of asynchronous events (after the end of the presynaptic train) for 22 interneuron to interneuron (total 1718 events) and 27 interneuron to PC pairs (total 2211 events). We found that the amplitude distribution is dependent on both presynaptic and postsynaptic cell type with large events being more frequent when PCs are postsynaptic or when TLCs are presynaptic (Fig. $7 F, G)$. For example, $>14 \%$ of asynchronous events from TLCs to PC have a peak amplitude of $>200 \mathrm{pA}$.

This skewed distribution of quantal amplitudes makes it impossible to derive the exact number and timing of vesicles re- 

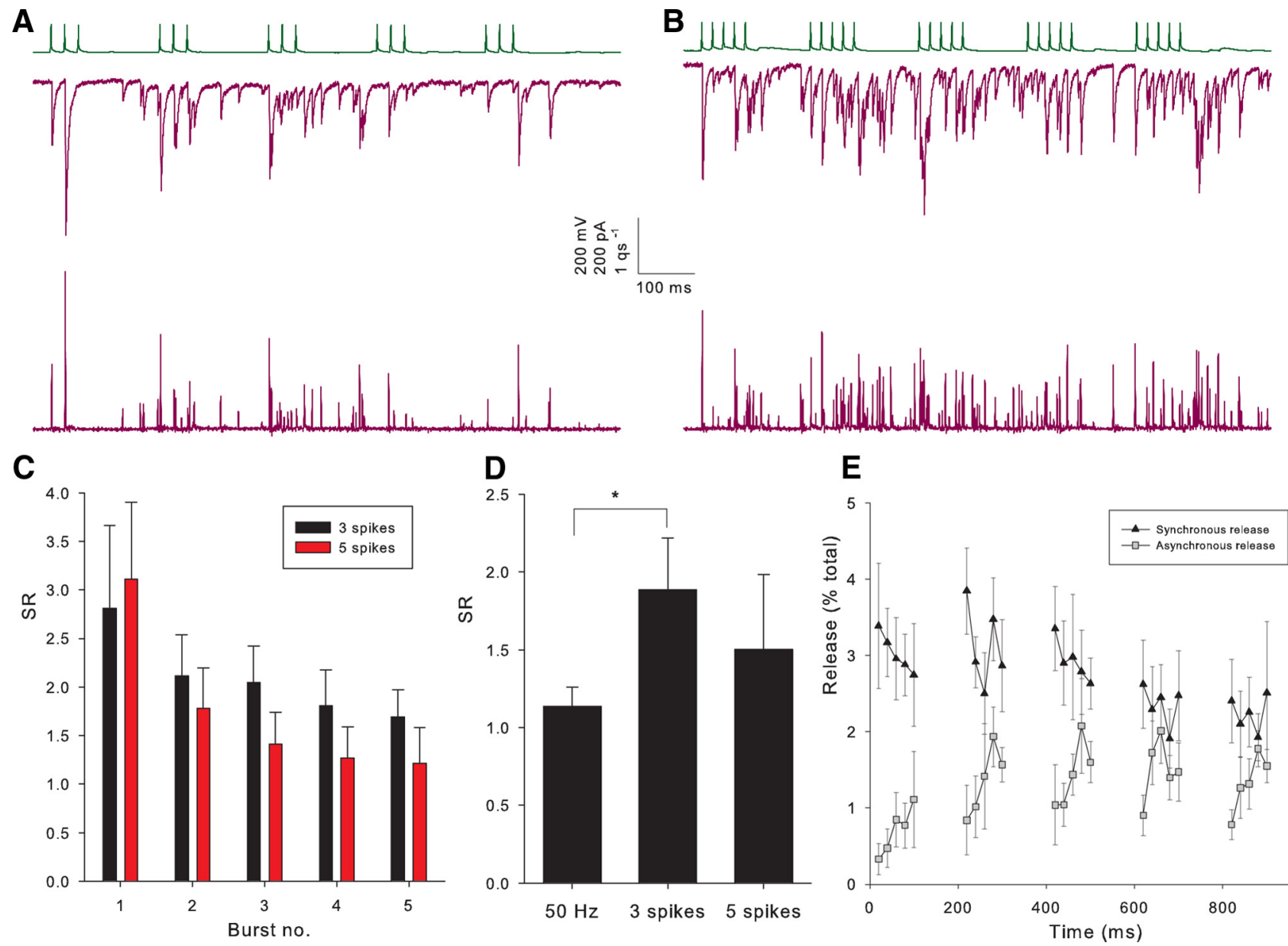

$100 \mathrm{~ms}$

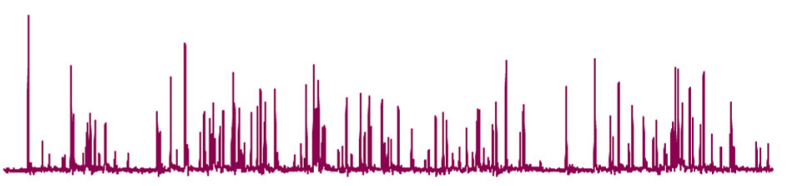

C
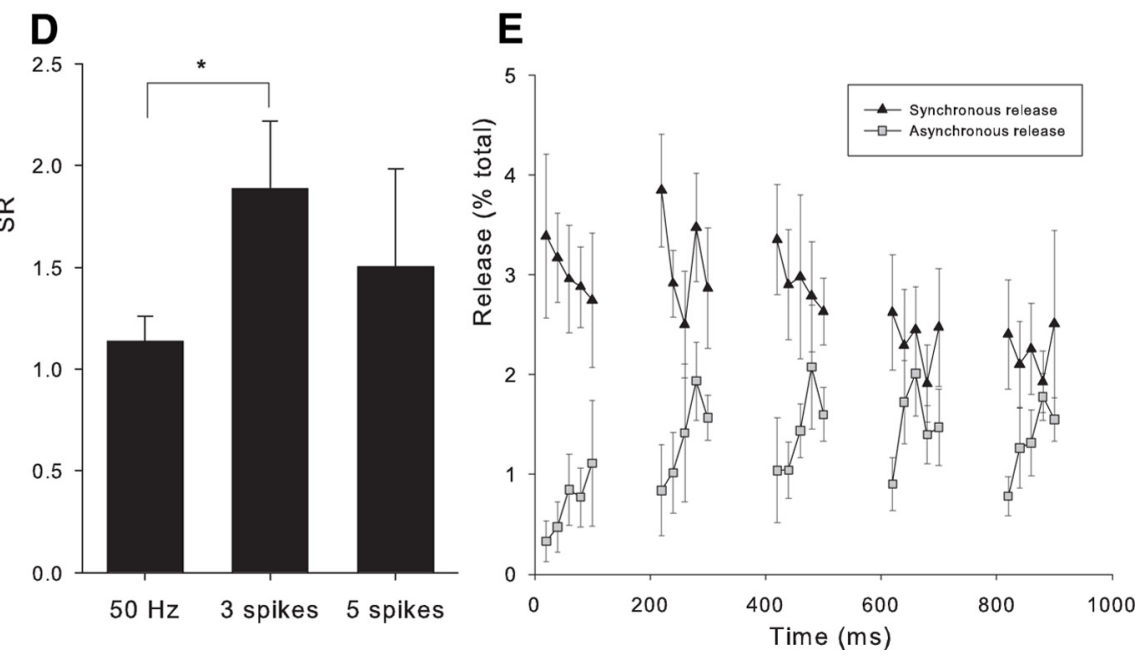

Figure 8. Asynchronous in response to natural trains of action potentials. A, Example recording of TLC (upper trace) to PC (middle trace) pair during a train of 5 bursts of 3 spikes at $40 \mathrm{~Hz}$. Lower trace shows release rate histogram. $\boldsymbol{B}$, Same pair shown in $A$ during a train of 5 bursts of 5 spikes at $50 \mathrm{~Hz}$. C, Histogram showing SR during each burst (from start of first burst to the start of the second burst, etc.) for three and five spikes for all pairs. $\boldsymbol{D}$, Histogram of SR for entire train for all pairs in $50 \mathrm{~Hz}$ trains, three spike bursts and five spike bursts $(50 \mathrm{~Hz}, n=12 ; 3$ spikes, $n=12 ; 5$ spikes, $n=$ 6). ${ }^{*} p<0.05$. E, Plot showing asynchronous and synchronous release for individual spikes as a percentage of the total release during the train for all five spike bursts. All recordings are in CA1.

leased by deconvolution from a mean value of quantal amplitude. The purpose of this study, however, is not to determine the exact number of vesicles released, rather, it is to determine the time course of inhibitory drive to the postsynaptic cell produced by transmitter released throughout the train. As such, although the units used may be invalid, the conclusions we have drawn are not. This does, however, show that great care should be used in interpreting the results of this type of analysis.

\section{Asynchronous in response to natural trains}

We have shown that neurotransmitter release becomes desynchronized in response to $50 \mathrm{~Hz}$ trains of action potentials; however, such long trains may be unlikely to occur in vivo. We studied the time course of release from CCK interneurons in response to trains of action potentials designed to mimic natural firing. In vivo recordings in anesthetized rats have shown that CCK interneurons are highly active during theta oscillations firing several times during each cycle (Klausberger et al., 2005). To reproduce this, we induced five bursts of three action potentials with an intraburst frequency of $40 \mathrm{~Hz}$ and an interburst frequency of $5 \mathrm{~Hz}$ (theta frequency). We found that release became desynchronized during these trains (Fig. $8 \mathrm{~A}, \mathrm{C}$ ) with an SR for the entire train of $1.9 \pm 0.3(n=12)$ compared with an SR of $1.13 \pm 0.1$ for $50 \mathrm{~Hz}$ trains in the same pairs. Klausberger et al. (2005) also reported that in awake, behaving animals CCK interneurons probably fire even more frequently, so to mimic this we induced five $50 \mathrm{~Hz}$ bursts of five action potentials again at $5 \mathrm{~Hz}$ in a subset of recordings. We also find a high proportion of asynchronous release in response to these trains (Fig. $8 B-E)$ with an SR for the entire train of $1.6 \pm 0.4(n=6, p=0.6$ vs 3 spike trains). Figure $8 E$ shows that the amount of asynchronous release increases throughout these bursts and then decays until the start of the next burst. This shows that asynchronous release will have the greatest functional significance when CCK interneurons fire bursts of at least five action potentials.

\section{Discussion}

In this study, we have shown that the synchrony of GABA release during trains of presynaptic action potentials is highly variable and is dependent on the class of presynaptic interneuron but independent of postsynaptic cell type. In particular, synchronicity is highest in PV BCs and lowest in BSCs and TLCs with CCK $\mathrm{BCs}$ intermediate. This discrepancy is largely attributable to release later in the train, with all cell types mediating mainly synchronous release for the first five action potentials. We find that the asynchronous release increases more rapidly than synchronous release with increasing $\left[\mathrm{Ca}^{2+}\right]_{\mathrm{E}}$. We also find that even in the highly asynchronous activity which follows the end of the presynaptic train, large individual IPSCs occur which persist in low $\left[\mathrm{Ca}^{2+}\right]_{\mathrm{E}}$ and $\mathrm{Sr}^{2+}$, suggesting very large quantal events. Fi- 
nally, we show that asynchronous release also occurs in response to natural trains of presynaptic action potentials.

These findings confirm and expand a previous finding in the dentate gyrus (Hefft and Jonas, 2005), in which CCK-positive interneurons mediate asynchronous transmitter release onto granule cells. These neurons have a similar axonal distribution to the BSCs we recorded from, and the asynchrony of release appears similar to that reported here. Compared with BSCs, CCK BCs show a smaller, but still large, amount of asynchronous release, and we found a further highly asynchronous class of interneuron in TLCs. The relatively low level of CCK immunoreactivity in the granule cell layer suggests that these cell classes may not have a counterpart in the dentate gyrus (Hefft and Jonas, 2005). BSCs are classically defined as fast-spiking, PV-containing cells (Somogyi and Klausberger, 2005), and as such, the cells in this study may more closely resemble those often referred to as Schaffer-associated cells (Vida et al., 1998), but CCK-containing, nonfast spiking cells have also been previously termed BSCs (Pawelzik et al., 2002), a term we use because of the presence of these cells in the absence of Schaffer collaterals in CA3. Pawelzik et al. (2002) also report CCK immunoreactivity in cells they term wide-arbor basket cells that closely resemble our TLCs. TLCs reported here should not be confused with the mGluR8expressing trilaminar cell with a projection to the subiculum (Ferraguti et al., 2005) but may correspond to apical dendritic targeting cells [proposed type 9 interneurons (Klausberger and Somogyi, 2008)]. We have shown that BSCs and TLCs cell classes included in this study represent CCK-containing interneurons both directly using scRT-PCR and indirectly by demonstrating the expression of DSI (Pitler and Alger, 1992; Katona et al., 1999; Wilson et al., 2001; Földy et al., 2007).

Inhibition by hippocampal interneurons can act to synchronize activity (Cobb et al., 1995) by allowing action potential firing only in a narrow temporal window via feedforward inhibition (Pouille and Scanziani, 2001). The properties of PV-containing interneurons are particularly well suited to imposing temporal precision (Freund, 2003), and PV-containing or fast-spiking interneurons are the main mediators of feedforward inhibition in many brain areas (Liu et al., 2002; Mallet et al., 2005; Daw et al., 2007). Maintaining synchrony of release throughout trains of presynaptic activity is clearly vital for carrying out this function. It seems likely that the function of the profound asynchrony of release in CCK BCs, BSCs, and TLCs is to "smooth out" the total inhibitory drive to postsynaptic cells resulting in a prolonged temporal window of inhibition of postsynaptic spiking, which can extend beyond the entire period of presynaptic activity (Hefft and Jonas, 2005). We have shown that this smoothing of inhibition is not restricted to one presynaptic/postsynaptic cell-type combination but occurs at synapses made by a whole group of CCK-expressing interneuron classes onto a wide range of postsynaptic cell types. A similar lack of dependence on postsynaptic cell type has also recently been reported for CCK BCs (Karson et al., 2009). Activation of these cells, therefore, will result in an episode of dampened activity in multiple somatodendritic domains of all cells in a region of the hippocampus. Furthermore, whereas CCK cells fire preferentially during a specific phase of theta oscillations (Klausberger et al., 2005), our recordings suggest that the inhibition of postsynaptic firing they impose will be effective throughout the period of theta oscillation.

Many properties of presynaptic terminals have been shown to be specific to the identity of the target cell including presynaptic receptor expression (Shigemoto et al., 1996) and short-term (Scanziani et al., 1998) and long-term (Maccaferri et al., 1998) plasticity (for review see (Pelkey and McBain, 2007). The finding that SR is independent of target cell identity, therefore, suggests that asynchronous release is fundamental to the function of these cells and that CCK cells are specialized to regulate the overall activity of their local region of the hippocampus.

No consensus exists as to the mechanisms leading to asynchronous release. In fact, the calcium dependence has been shown to be both lower (Sun et al., 2007) and higher (Goda and Stevens, 1994) affinity than that for synchronous release. Alternatively, asynchronous release has been attributed to the build up of residual or bulk calcium ( $\mathrm{Lu}$ and Trussell, 2000; Otsu et al., 2004) during bursts of activity. Knock out of isoforms of the presynaptic calcium sensor synaptotagmin at the calyx of Held (synaptotagmin 2) (Sun et al., 2007) or dentate granule cell synapses (synaptotagmin 1) (Kerr et al., 2008) selectively blocks synchronous release, revealing asynchronous release in its place, showing that separate calcium sensors mediate synchronous and asynchronous release. Different calcium dependence of synchronous and asynchronous release in our study is consistent with two calcium sensors, such as separate synaptotagmin isoforms, being responsible for the two modes of release from an individual cell. If varying proportions of transmitter release in the different cell types is mediated by each of these sensors it would result in different SR.

Mean mIPSC amplitude in hippocampal cells recorded with near symmetrical $\left[\mathrm{Cl}^{-}\right]$has often been reported to be in the range of 30-40 pA ( 0.4-0.6 nS) (Capogna et al., 1993; Thompson et al., 1997). As such, our finding that quantal events can have amplitudes $>500 \mathrm{pA}(\sim 7 \mathrm{nS})$ is surprising. Such large miniature conductances are not, however, unprecedented: conductances up to $13.6 \mathrm{nS}$ for mEPSCs at mossy fiber-CA3 pyramidal cell synapses (Henze et al., 2002) and almost $12 \mathrm{nS}$ for mISPCs in cerebellar stellate cells (Nusser et al., 1997) have been reported. Quantal size up to $94 \mathrm{pA}(\sim 1.3 \mathrm{nS})$ has been calculated for CCK interneuron synapses onto CA3 pyramidal cells (Biró et al., 2006). Biró et al. (2006), however, predict that much larger currents occur at individual synapses as a result of multivesicular release being misinterpreted as release at separate sites. The insensitivity of the largest events to low $\left[\mathrm{Ca}^{2+}\right]_{\mathrm{E}}$ or $\mathrm{Sr}^{2+}$ suggests that multivesicular release is unlikely to be important in our study. Indeed, multivesicular release is greatly reduced at nearphysiological $\left[\mathrm{Ca}^{2+}\right]_{\mathrm{E}}$ (Biró et al., 2006), similar to that which we used. In the cerebellum, the large variability in mIPSC amplitude closely mirrors the variability in synaptic area, which is proportional to GABA receptor number as determined by immunogold labeling (Nusser et al., 1997). A 10-fold range in synaptic area determined at EM level was also found at CCK interneuron synapses in the hippocampus (Biró et al., 2006) from a sample of only 25 synapses, so variation in postsynaptic receptor number could well account for the $\sim 25$-fold range ( $20-500 \mathrm{pA}$ ) of IPSC amplitudes seen here. We have also shown that these large amplitude quantal events are more common when TLCs or BSCs are presynaptic. This may in part explain the large variability in amplitude and high proportion of failures seen in IPSCs from these cells; i.e., large amplitude connections formed by these interneurons may be mediated by a very small number of connections of which one or more produce large amplitude IPSCs. Such large quantal amplitudes, which create brief periods of high inhibitory drive, are at odds with the role of asynchronous release in smoothing inhibition. If, however, a large number of CCK interneurons are active during the same time period the overall result would still be an episode of smoothed inhibition.

We have shown here that highly asynchronous release is a common property of multiple interneuron classes, innervating multiple somatodendritic domains of a variety of postsynaptic cells. These 
interneurons are ideally suited to produce prolonged inhibitory episodes throughout a whole region of the hippocampus.

\section{References}

Aponte Y, Lien CC, Reisinger E, Jonas P (2006) Hyperpolarizationactivated cation channels in fast-spiking interneurons of rat hippocampus. J Physiol 574:229-243.

Atluri PP, Regehr WG (1998) Delayed release of neurotransmitter from cerebellar granule cells. J Neurosci 18:8214-8227.

Biró AA, Holderith NB, Nusser Z (2006) Release probability-dependent scaling of the postsynaptic responses at single hippocampal GABAergic synapses. J Neurosci 26:12487-12496.

Brager DH, Luther PW, Erdélyi F, Szabó G, Alger BE (2003) Regulation of exocytosis from single visualized GABAergic boutons in hippocampal slices. J Neurosci 23:10475-10486.

Capogna M, Gähwiler BH, Thompson SM (1993) Mechanism of mu-opioid receptor-mediated presynaptic inhibition in the rat hippocampus in vitro. J Physiol 470:539-558.

Cauli B, Audinat E, Lambolez B, Angulo MC, Ropert N, Tsuzuki K, Hestrin S, Rossier J (1997) Molecular and physiological diversity of cortical nonpyramidal cells. J Neurosci 17:3894-3906.

Cobb SR, Buhl EH, Halasy K, Paulsen O, Somogyi P (1995) Synchronization of neuronal activity in hippocampus by individual GABAergic interneurons. Nature 378:75-78.

Daw MI, Ashby MC, Isaac JT (2007) Coordinated developmental recruitment of latent fast spiking interneurons in layer IV barrel cortex. Nat Neurosci 10:453-461.

Diamond JS, Jahr CE (1995) Asynchronous release of synaptic vesicles determines the time course of the AMPA receptor-mediated EPSC. Neuron 15:1097-1107.

Ferraguti F, Klausberger T, Cobden P, Baude A, Roberts JD, Szucs P, Kinoshita A, Shigemoto R, Somogyi P, Dalezios Y (2005) Metabotropic glutamate receptor 8-expressing nerve terminals target subsets of GABAergic neurons in the hippocampus. J Neurosci 25:10520-10536.

Földy C, Lee SY, Szabadics J, Neu A, Soltesz I (2007) Cell type-specific gating of perisomatic inhibition by cholecystokinin. Nat Neurosci 10:1128-1130.

Freund TF (2003) Interneuron diversity series: rhythm and mood in perisomatic inhibition. Trends Neurosci 26:489-495.

Freund TF, Buzsáki G (1996) Interneurons of the hippocampus. Hippocampus 6:347-470.

Goda Y, Stevens CF (1994) Two components of transmitter release at a central synapse. Proc Natl Acad Sci U S A 91:12942-12946.

Goldberg EM, Clark BD, Zagha E, Nahmani M, Erisir A, Rudy B (2008) K+ channels at the axon initial segment dampen near-threshold excitability of neocortical fast-spiking GABAergic interneurons. Neuron 58:387-400.

Hefft S, Jonas P (2005) Asynchronous GABA release generates long-lasting inhibition at a hippocampal interneuron-principal neuron synapse. Nat Neurosci 8:1319-1328.

Henze DA, McMahon DB, Harris KM, Barrionuevo G (2002) Giant miniature EPSCs at the hippocampal mossy fiber to CA3 pyramidal cell synapse are monoquantal. J Neurophysiol 87:15-29.

Isaacson JS, Walmsley B (1995) Counting quanta: direct measurements of transmitter release at a central synapse. Neuron 15:875-884.

Karson MA, Tang AH, Milner TA, Alger BE (2009) Synaptic cross talk between perisomatic-targeting interneuron classes expressing cholecystokinin and parvalbumin in hippocampus. J Neurosci 29:4140-4154.

Katona I, Sperlágh B, Sík A, Käfalvi A, Vizi ES, Mackie K, Freund TF (1999) Presynaptically located CB1 cannabinoid receptors regulate GABA release from axon terminals of specific hippocampal interneurons. J Neurosci 19:4544-4558.

Kawaguchi Y, Katsumaru H, Kosaka T, Heizmann CW, Hama K (1987) Fast spiking cells in rat hippocampus (CA1 region) contain the calciumbinding protein parvalbumin. Brain Res 416:369-374.

Kerr AM, Reisinger E, Jonas P (2008) Differential dependence of phasic transmitter release on synaptotagmin 1 at GABAergic and glutamatergic hippocampal synapses. Proc Natl Acad Sci U S A 105:15581-15586.

Klausberger T, Somogyi P (2008) Neuronal diversity and temporal dynamics: the unity of hippocampal circuit operations. Science 321:53-57.

Klausberger T, Marton LF, O’Neill J, Huck JH, Dalezios Y, Fuentealba P, Suen WY, Papp E, Kaneko T, Watanabe M, Csicsvari J, Somogyi P (2005) Complementary roles of cholecystokinin- and parvalbumin-expressing
GABAergic neurons in hippocampal network oscillations. J Neurosci 25:9782-9793.

Kraushaar U, Jonas P (2000) Efficacy and stability of quantal GABA release at a hippocampal interneuron-principal neuron synapse. J Neurosci 20:5594-5607.

Lambolez B, Audinat E, Bochet P, Crépel F, Rossier J (1992) AMPA receptor subunits expressed by single Purkinje cells. Neuron 9:247-258.

Landfield PW, Pitler TA, Applegate MD (1986) The effects of high $\mathrm{Mg}^{2+}$ to- $\mathrm{Ca}^{2+}$ ratios on frequency potentiation in hippocampal slices of young and aged rats. J Neurophysiol 56:797-811.

Liu CL, Wang YJ, Chen JR, Tseng GF (2002) Parvalbumin-containing neurons mediate the feedforward inhibition of rat rubrospinal neurons. Anat Embryol 205:245-254.

López-Bendito G, Sturgess K, Erdélyi F, Szabó G, Molnár Z, Paulsen O (2004) Preferential origin and layer destination of GAD65-GFP cortical interneurons. Cereb Cortex 14:1122-1133.

Lu T, Trussell LO (2000) Inhibitory transmission mediated by asynchronous transmitter release. Neuron 26:683-694.

Maccaferri G, Tóth K, McBain CJ (1998) Target-specific expression of presynaptic mossy fiber plasticity. Science 279:1368-1370.

Mallet N, Le Moine C, Charpier S, Gonon F (2005) Feedforward inhibition of projection neurons by fast-spiking GABA interneurons in the rat striatum in vivo. J Neurosci 25:3857-3869.

McBain CJ, Fisahn A (2001) Interneurons unbound. Nat Rev Neurosci 2:11-23.

Nusser Z, Cull-Candy S, Farrant M (1997) Differences in synaptic GABA(A) receptor number underlie variation in GABA mini amplitude. Neuron 19:697-709.

Otsu Y, Shahrezaei V, Li B, Raymond LA, Delaney KR, Murphy TH (2004) Competition between phasic and asynchronous release for recovered synaptic vesicles at developing hippocampal autaptic synapses. J Neurosci 24:420-433.

Pawelzik H, Hughes DI, Thomson AM (2002) Physiological and morphological diversity of immunocytochemically defined parvalbumin- and cholecystokinin-positive interneurones in CA1 of the adult rat hippocampus. J Comp Neurol 443:346-367.

Pelkey KA, McBain CJ (2007) Differential regulation at functionally divergent release sites along a common axon. Curr Opin Neurobiol 17:366-373.

Pitler TA, Alger BE (1992) Postsynaptic spike firing reduces synaptic GABAA responses in hippocampal pyramidal cells. J Neurosci 12:4122-4132.

Poncer JC, Shinozaki H, Miles R (1995) Dual modulation of synaptic inhibition by distinct metabotropic glutamate receptors in the rat hippocampus. J Physiol 485:121-134.

Pouille F, Scanziani M (2001) Enforcement of temporal fidelity in pyramidal cells by somatic feed-forward inhibition. Science 293:1159-1163.

Scanziani M, Gähwiler BH, Charpak S (1998) Target cell-specific modulation of transmitter release at terminals from a single axon. Proc Natl Acad Sci U S A 95:12004-12009.

Shigemoto R, Kulik A, Roberts JD, Ohishi H, Nusser Z, Kaneko T, Somogyi P (1996) Target-cell-specific concentration of a metabotropic glutamate receptor in the presynaptic active zone. Nature 381:523-525.

Somogyi P, Klausberger T (2005) Defined types of cortical interneurone structure space and spike timing in the hippocampus. J Physiol 562:9-26.

Sun J, Pang ZP, Qin D, Fahim AT, Adachi R, Südhof TC (2007) A dual$\mathrm{Ca}^{2+}$-sensor model for neurotransmitter release in a central synapse. Nature 450:676-682.

Thompson SM, Poncer JC, Capogna M, Gähwiler BH (1997) Properties of spontaneous miniature GABAA receptor mediated synaptic currents in area CA3 of rat hippocampal slice cultures. Can J Physiol Pharmacol 75:495-499.

Vida I, Halasy K, Szinyei C, Somogyi P, Buhl EH (1998) Unitary IPSPs evoked by interneurons at the stratum radiatum-stratum lacunosummoleculare border in the CA1 area of the rat hippocampus in vitro. J Physiol 506:755-773.

Whittington MA, Traub RD (2003) Interneuron diversity series: inhibitory interneurons and network oscillations in vitro. Trends Neurosci 26:676-682.

Wilson RI, Kunos G, Nicoll RA (2001) Presynaptic specificity of endocannabinoid signaling in the hippocampus. Neuron 31:453-462.

Younkin SG (1974) An analysis of the role of calcium in facilitation at the frog neuromuscular junction. J Physiol 237:1-14.

Zhang C, Szabó G, Erdélyi F, Rose JD, Sun QQ (2006) Novel interneuronal network in the mouse posterior piriform cortex. J Comp Neurol 499: $1000-1015$. 